\title{
O CONCEITO DE ESSÊNCIA HUMANA A PARTIR DA CONCEPÇÃO ANTROPOLÓGICA DE LUDWIG FEUERBACH
}

\author{
Jéfferson Luiz Schafranski da Silva ${ }^{1}$ \\ Charles Feldhaus ${ }^{2}$
}

\begin{abstract}
Resumo:
O presente artigo busca apresentar a concepção de essência humana materialista antropológica de Feuerbach. Ao longo de seu pensamento, Feuerbach, procura esclarecer que pensar o homem, significa pensá-lo dentro dos limites da condição humana material sensível e física. Portanto é enfatizado que Feuerbach sustenta que o acesso a nossa essência está relacionado com a maneira como acessamos a nossa consciência e que a maneira como acessamos essa última tem uma condição estritamente material e, portanto, deveríamos abordá-la exatamente dessa maneira e não como algo fora de nós e meramente abstrato como a filosofia especulativa. A essência humana não alienada é resultado de uma relação adequada do ser humano com aqueles atributos que são estritamente humanos, que são razão, vontade e coração. Por fim, pretende-se apresentar como Feuerbach compreende a essência humana e qual deve ser a condição para o contato de forma não alienada do homem com a mesma, bem como o que é necessário para possibilitar tal contato.
\end{abstract}

Palavras-chave: Antropologia. Consciência. Essência. Materialismo.

\section{THE CONCEPT OF HUMAN ESSENCE ON THE ANTHROPOLOGICAL CONCEPTION OF LUDWIG FEUERBACH}

\begin{abstract}
:
The present article seeks to present the Feuerbach's anthropological materialistic conception of human essence. Feuerbach tries to clarify that the human essence should be understood within the limits of the material human condition, what includes too the sensible and physical parts of a human being. It is also intended to emphasize that Feuerbach mantain that the acess to our essence is related to the way we acess the human consciousness and our acess to it has a strictly material condition and also we should approach it exactly this way and not something outside of us or merely abstract as was done by speculative philosophy. The non-alienated human essence is the result of an adequate relation of the human being with those attributes that are strictly human, which are reason, will and heart. Finally, it is intended to present how Feuerbach understands the human essence and what should be the condition for man's contact with his own essence in a non-alienated way, and what is necessary to enable such contact.
\end{abstract}

Keywords: Antropology. Consciousness. Essence. Materalism.

1 Jefferson Schafranski é mestre em filosofia pela Universidade Estadual de Londrina. E-mail: jeffersonschafranskiwb@yahoo.com.br

2 Charles Feldhaus é professor Adjunto D da Universidade Estadual de Londrina. Professor permanente do programa de mestrado acadêmico em filosofia da Universidade Estadual de Londrina. E-mail: charlesfeldhaus@gmail.com 


\section{INTRODUÇÃO}

Se poderia dizer que, ao menos ao público não especializado no pensamento de Ludwig Feuerbach (1804-1872), o mesmo é ainda pouco conhecido e divulgado em especial no que diz respeito ao idioma português, particularmente no Brasil, onde ainda é bastante raro encontrar algum estudo mais abrangente e aprofundado da obra do pensador. Para muitos, ele ainda é lembrado apenas com um pensador que influenciou a guinada materialista da filosofia empreendida por Karl Marx; razão pela qual este estudo pretende apresentar uma visão mais detalhada da concepção e posição feuerbachiana a respeito do conceito de essência humana. Partindo de uma interpretação centrada na sua produção filosófica e em suas obras, este artigo procura remeter-se ao ponto chave da discussão feuerbachiana acerca da concepção de essência para o homem. Feuerbach é um pensador do século XIX que possui grande relevância e destaque, uma vez que é ele responsável por romper com a tradição filosófica de sua época, a tradição hegeliana. Embora seja ele um hegeliano, por ter sido orientado diretamente por Hegel, identifica-se nele um pensamento contrário ao de seu mestre, configurando-o como um dos primeiros hegelianos de esquerda. Enquanto aluno de Hegel, Feuerbach bebeu da fonte do pensamento de seu mestre, motivo pelo qual levou-o a discordar do mesmo, isto é, Feuerbach se utiliza da formação tida junto a seu mestre Hegel, para a partir daí propor em um primeiro momento uma crítica ao idealismo hegeliano e posteriormente apresentar uma nova proposta filosófica não mais baseada na condição abstrata e metafísica do idealismo, mas sim baseada na condição humana sensível e material.

Feuerbach dentro de sua produção filosófica, apresenta uma condição nova para a filosofia, por ser ele o responsável por apresentar uma explicação de homem totalmente contrária a proposta vigente, a proposta do idealismo. A partir de uma postura totalmente antropológica materialista, procura apresentar o homem, bem como sua condição para auto interpretação, ou seja, a condição para o contato com a essência, baseando tal conjectura na posição humana que é uma posição material e sensível e, por conseguinte fundamentada na limitação. Feuerbach procura apresentar que a consciência humana, assim como a essência humana são condições que se apresentam dentro da realidade humana e, por sua vez, deve-se tratar justamente da condição da limitação. Sua postura consequentemente se posiciona contrária a proposta filosófica vigente de seu tempo, precisamente por conter este algo de novo e avesso ao idealismo.

Feuerbach trata a limitação humana como condição para explicar o homem, visto que para se construir tal explicação, segundo ele é necessário que se aborde e trate da

\begin{tabular}{|c|c|c|c|c|}
\hline Q Rovista Qialectus & Ano 5 & n. 12 & Janeiro - Julho 2018 & p. $284-302$ \\
\hline
\end{tabular}


limitação ou mesmo do estado de finitude ao qual o homem se encontra dentro da realidade. A grande novidade de seu pensamento se constitui exatamente porque é ele responsável por trazer para dentro da discussão filosófica a condição material e sensível humana, que é uma condição dotada precisamente da finitude, visto que a realidade a qual é possível para o homem um auto entendimento, é uma realidade que está condicionada à finitude e por consequência, algo que deve ser trazido para dentro da discussão filosófica acerca do homem.

Para se pensar, ou mesmo para se discutir o conceito de essência humana em Feuerbach, é necessário que se considere a questão da limitação humana. De maneira que, para que seja possível uma proposição daquilo que é o homem, ou daquilo que o homem significa - sua essência -, ou mesmo daquilo que é preciso para alcançar tal significado - a consciência -, é de extrema relevância que se considere que tal discussão só é possível dentro e a partir da realidade humana, que por sua vez é uma realidade dotada da sensibilidade, da materialidade e por consequência da limitação.

Nesse sentido, Feuerbach procura apresentar o que seria essência humana e, qual seria a condição necessária para se alcançar tal força, sendo essa condição o resgate e uso da consciência. A essência humana se define em Feuerbach como a explicação que o homem possui de si, isto é, a essência significa a definição daquilo que é o homem precisamente enquanto humano. Para tanto Feuerbach vai propor que esta definição e significação só é possível quando o homem percebe que esta força está na natureza humana, ou seja, a essência do homem está dentro da própria condição humana e, de maneira alguma é algo que lhe fora dado a partir de uma condição abstrata.

A essência humana para Feuerbach é aquilo que define o homem e, por sua vez só pode ser algo que produz dentro do próprio humano e, consequentemente deve ser acessado pelo mesmo. Nesse sentido, uma vez que tal condição não é algo que lhe vem de fora, mas sim algo que se produz e se encontra dentro da própria condição humana, Feuerbach identifica como papel da consciência possibilitar tal acesso ou resgate da essência. Sendo assim, a consciência se explica em nosso autor como esta força de reconhecimento do homem de si, em outras palavras, Feuerbach explica a consciência como a força humana capaz de explicar o homem, de maneira que é a consciência a capacidade humana de entendimento. Para tanto é propósito deste artigo ainda, explicar como se dá o processo da consciência, ou dizendo de outro modo, o que é preciso para que tal força se produza no homem, e seja reconhecida pelo mesmo, motivo que leva Feuerbach a apresentar a necessidade do homem de resgatar e reconhecer os atributos humanos como humanos, sendo eles a razão, a vontade e o coração.

\section{6}


A proposta desse artigo se encaminha então na direção de apresentar o que Ludwig Feuerbach entende e explica pela concepção de essência humana e, o que é preciso para que o homem possa reconhecer e alcançar esta essência. Desse modo, este artigo trabalhará com conceitos provindos das principais obras de Feuerbach, assim como também dialogará com seus principais comentadores e suas posições acerca do referido assunto.

\section{O CONCEITO DE ESSÊNCIA HUMANA EM FEUERBACH}

Ludwig Andreas Feuerbach desenvolve, ao longo de sua produção filosófica, uma concepção teológica e filosófica voltada para a compreensão do homem enquanto um ser integral dentro de pressupostos e atributos de caráter extremamente humanos em contraposição a concepções abstratas. Para tanto, elabora um pensamento filosófico com características antropológicas, as quais direcionam sua proposta de maneira a salientar e especificar a necessidade de uma explicação antropológica do que seja e como se desenvolve a consciência; o que se poderia chamar da essência humana, quais seus atributos e ainda o porquê ser necessário tratar sobre a essência humana. Uma compreensão adequada de como se desenvolve e de que seja a essência humana é uma etapa fundamental na identificação do método adequado de se fazer teologia e filosofia. Uma vez que se parte de uma concepção abstrata e transcendente do que seja Deus e do que seja o ser humano, se é levado a desenvolver também uma concepção teológica e filosófica inadequada. É inadequada porque o ser humano material é separado de sua essência e se aliena de si mesmo.

A grande novidade do pensamento de Feuerbach, que vale destaque, é a condição que o homem deve se impor frente ao mesmo homem, no sentido que possa se identificar como homem real, material e completo. O que Feuerbach tem como preocupação e, por conseguinte, o que se pretende neste momento, é explicar como funciona a concepção de homem, e ainda, como essa concepção acontece no homem de forma prática e não de maneira contemplativa, erro que o mesmo aponta ter sido cometido por seus antecessores, em especial por seu mestre - a saber, Hegel.

Neste sentido, o que se pretende na proposta feuerbachiana é justamente a compreensão, ou até mesmo uma tentativa de explicação, sobre o que é de fato o homem, o que o compõe e, o que o estrutura. A preocupação filosófica de Feuerbach está direcionada para a compreensão da estruturação do homem integral e completo, que é aquilo que ele define como ser em gênero, e em contrapartida também se preocupa em definir o que é aquilo que distancia o homem desta sua integridade que se define por essência.

\begin{tabular}{|c|c|c|c|c|}
\hline Q Rovista Qialectus & Ano 5 & n. 12 & Janeiro - Julho 2018 & p. $284-302$ \\
\hline
\end{tabular}


Assim sendo, a discussão que o autor desenvolve se direciona para a fundamentação daquilo compreendido como essência humana, uma vez que esta mesma essência deve estar fundamentada na própria concepção do homem real constante e material. O que se apresenta como objetivo nesta proposição é de fato a necessidade de uma posição materialista e antropológica sobre a compreensão de homem completo, integral e, por conseguinte, o motivo da cisão com esta integridade.

O pensamento do nosso filósofo se compõe dentro de uma compreensão do homem voltada exclusivamente para a própria condição humana. O que Feuerbach propõe como explicação do homem integral é a quebra com uma teologia que explica o homem, ou mesmo tenta explicar o homem, de forma ideal. A comentadora Alice Aleixo destaca: "Feuerbach visa à dignificação do homem como ente real e concreto, como um ser integral não dividido entre Deus no céu e César na terra. É preciso que o homem se lance na realidade, de corpo e alma, na unidade que lhe é adequada" (ALEIXO, 2009, p. 5). Aquilo que Feuerbach apresenta como proposta de explicação sobre o homem integral é uma discussão quase que ontológica do ser real. Dizendo de outro modo, a filosofia deste autor se explica a partir da tentativa de compreender o homem completo enquanto ser, porém este ser entendido como um ser real. Ou seja, a necessidade que se apresenta em Feuerbach é de explicar como o homem deve ser compreendido enquanto ser essencial, e como o mesmo tem acesso a esta essência que lhe é sua.

Na caracterização do homem integral, ou como se apresenta homem genérico, Feuerbach mostra a preocupação em esclarecer que o homem precisa da conexão com sua essência para que seja possível que se identifique enquanto ser real dentro da realidade humana. A preocupação de Feuerbach está em explicar como este processo de conexão com a essência funciona, e ainda em explicar qual a necessidade que o homem tem de se reconectar com esta essência que lhe foi cindida. Aquilo que se justifica neste momento é esclarecer porque Feuerbach se opõe ao idealismo, propriamente o de Hegel, e como nosso pensador se posiciona frente a condição e necessidade que o homem possui de primeiro compreender sua essência como sendo sua, e depois compreender e perceber que ele precisa estabelecer uma reconexão com esta essência. Num sentido que, para Feuerbach, a compreensão da essência humana não finda apenas na explicação da mesma, mas por sua vez na prática que deve se construir a partir deste processo de reconexão.

O que Feuerbach questiona, na posição hegeliana da dialética, é o caráter contraditório, que não produz na visão do nosso autor, um posicionamento suficiente para a compreensão da estruturação e da explicação da consciência humana. Para Feuerbach, a

\begin{tabular}{|c|c|c|c|c|}
\hline Q Rovista Qialectus & Ano 5 & n. 12 & Janeiro - Julho 2018 & p. $284-302$ \\
\hline
\end{tabular}


dialética tem como motor a autotransformação reflexiva de maneira prática e não puramente especulativa, assim como ele denuncia acontecer por parte de Hegel. Feuerbach já se posiciona contrário à posição hegeliana, em uma carta enviada a Hegel junto com sua dissertação doutoral, onde nosso pensador postula uma cisão com a filosofia especulativa hegeliana:

\begin{abstract}
[...] Igualmente pela consciência de que as ideais produzidas ou despertadas em mim por meio de você e expressadas em sua filosofia não ficam acima do sensível e do fenômeno em geral, mas continuam a agir de forma criativa. [...] e, também, essa dissertação minha, pelo menos em geral, e embora de forma que com enorme imperfeição, imprecisão grosseira, ainda não saiba como render-se do abstrato, traz em si o traço de uma forma de filosofar que poderia ser chamado de realização e a mundanização da ideia, a assarkosis ou a encarnação do puro logos. Esta consciência, portanto, independentemente das deficiências do meu trabalho, sentidas e reconhecidas por mim mesmo, me dá coragem de enviar esse meu trabalho. Da mesma forma, estou firmemente convencido de que essa maneira de filosofar que, embora ainda não liberada ou desvinculada de mim mesmo, apareça apenas nessa obra em estouros, que existe no meu interior ainda como no processo de tornar-se e que, pelo menos através de mim, nunca leva à existência e a uma conformação completa, está na época, ou (o que é o mesmo) está baseada no espírito da filosofia moderna e até mesmo o mais contemporâneo, surge desse mesmo espírito (FEUERBACH, 1993, p. 9, tradução nossa).
\end{abstract}

A necessidade identificada por Feuerbach em propor uma crítica frente à filosofia de Hegel, e posteriormente, este distanciamento que ocorre entre os dois está fundamentado na questão que Feuerbach define como a falta de uma postura propriamente material por parte de Hegel. O que fortalece o distanciamento, e a consequente formulação de uma teoria autêntica por parte de Feuerbach, é a condição exposta pelo pensador sobre a postura tomada por Hegel na condição do idealismo. Hegel chega a postular uma análise essencial do homem, o problema, indica Feuerbach, é que Hegel acaba por fazer isso de forma especulativa e não de maneira efetiva e temporal. Feuerbach declara que a proposta hegeliana acerca daquilo que o próprio Hegel intitula espírito, é uma proposta que não passa por uma efetivação, uma vez que, o espírito não se reconhece dentro de uma condição real. De tal maneira evidenciado que o mesmo Feuerbach assim comenta em um de seus textos, intitulado "Para a crítica da filosofia de Hegel":

O espírito de Hegel é lógico, determinado, (sit venia verbo [se me é assim permitido]) um espírito entomológico, isto é, um espírito que só encontra o seu local apropriado num corpo com muitos membros salientes, com incisões e segmentações profundas. Esse espírito revela-se principalmente na sua intuição e tratamento da história. Hegel fixa e expõe unicamente as diferenças mais salientes das diversas religiões, filosofias, épocas e povos, e fá-lo apenas numa progressão ascendente; o comum, o igual é inteiramente relegado para segundo plano. A própria forma de sua intuição e método é apenas o tempo exclusivista, e não simultaneamente o espaço tolerante; o seu sistema só reconhece subordinação e sucessão, mas desconhece coordenação e coexistência (FEUERBACH, 2012, p. 24). 
Esta intuição que faz parte do método hegeliano, que aparece claramente nas suas primeiras e principais obras - a saber, Ciência da Lógica e Fenomenologia do Espírito -, destaca o caráter puramente idealista do espírito, de maneira a salientar apenas a concepção de um espírito determinado e de forma alguma uma concepção de espírito essencial. O que Feuerbach aponta como sendo o erro de Hegel é o tratamento meramente histórico dado à construção do espírito, sem levar em consideração aquilo que Feuerbach reconhece como parte estruturante e fundamental da construção da essência, esta parte estruturante seria a condição de material sentimental e sagrado. A produção histórica do ser, ou ainda da essência, acontece para Feuerbach não em um aspecto puramente contemplativo como em Hegel, mas acontece contrariamente de maneira real e dialética, sendo que esta dialética podendo ser entendida pela forma socrático-platônica de diálogo, algo a ser elucidado adiante.

Feuerbach não reconhece a contrariedade dialética como fonte da existência e da essência, uma vez que a contrariedade que a mesma propõe não fundamenta para Feuerbach a identidade do ser em gênero. O comentador Eduardo Chagas salienta muito bem na apresentação da obra "Para a crítica da filosofia de Hegel" de Feuerbach: "Feuerbach nega aqui, em sua crítica a Hegel, essa identidade lógica de ser e pensar, pois, para ele, apenas o ser concreto, real, sensível, é ser, porquanto em seu conceito está já implícito o conceito de existência, de determinidade de realidade e/ou objetividade" (CHAGAS, 2012, p. 14). Cabe ressaltar que a contrariedade frente à produção hegeliana, se apresenta no sentido de justificar o porquê de o idealismo propriamente de Hegel, com sua proposta lógica, não completa a explicação do homem completo, pois isto só pode acontecer quando se pensa um ser concreto e puramente sensível, dotado de atribuições completamente sensíveis. Todavia, o nosso pensador acaba por não desconsiderar a prática dialética, mas sim desconsidera a teoria hegeliana dialética.

Nesse contexto, salienta-se a postura assumida por Feuerbach sobre uma concepção prática do homem, contrária à posição idealista. A postura assumida por Feuerbach se apresenta como a condição de reconhecer para si um movimento que se identifica por dialética. A dialética feuerbachiana se afirma como um diálogo dentro da reconstrução da essência humana, que se salienta a partir do diálogo, diálogo este que, segundo nosso autor acontece por parte da consciência. A consciência tem a condição de postular sua própria identificação, que é algo que só acontece no fundamentar deste diálogo. Este diálogo é algo que acontece de maneira a despertar no homem, esta conversa consigo mesmo, na tentativa de auto reconhecimento. A dialética feuerbachiana, que se transforma em um realismo e

\begin{tabular}{|c|c|c|c|c|}
\hline Qovista Dialectus & Ano 5 & n. 12 & Janeiro - Julho 2018 & p. $284-302$ \\
\hline
\end{tabular}


materialismo frente ao idealismo, se transformam na contrapartida de uma posição de Hegel, que desconsidera a condição do humano enquanto ser real.

Para Feuerbach, o processo dialético ocorre justamente na composição deste diálogo interno, que propõe um reconectar por parte do humano, consigo mesmo - de tal forma que a dialética em Feuerbach se assemelha a dialética marxista, quando Feuerbach tem por objetivo explicar a consciência, ressaltando que isso em nosso autor acontece de maneira a produzir um processo, muitas vezes, interno de descoberta e redescoberta. Cabe ressaltar que em Feuerbach este diálogo não é apenas interno, mas também se constrói de modo externo, algo que será explanado posteriormente. Assim sendo, coloca-se para nosso autor a seguinte afirmação:

O método de Hegel vangloria-se de seguir o curso da natureza; ele inspira-se certamente na natureza, mas falta à cópia a vida do original. Sem dúvida que a natureza fez do homem o senhor dos animais, só que não lhe deu apenas mãos para domar os animais; deu-lhe também olhos e ouvidos para os admirar. A autonomia que a mão cruel rouba ao animal volta a ser-lhe restituída pelos olhos e ouvidos compadecidos (FEUERBACH, 2012, p. 24).

O que se evidencia em tal afirmação é que, embora a postura e método hegeliano se apresentem enraizados na natureza, ou mesmo no seu curso, a crítica postulada em toda a produção feuerbachiana é justamente o fato de existirem falhas nesse método. As falhas destacadas por esse posicionamento são, por conseguinte, as questões do não reconhecimento de uma estrutura de essência fundamentadas no próprio homem, e o fato de Hegel dar importância em demasia à imediaticidade da natureza, dada a natureza de caráter estruturante na teoria hegeliana. Para Feuerbach, a natureza não é algo imediato e sim, algo que se constrói e se apresenta na constituição do real e material, que, é algo que acontece efetivamente com a correlação coexistente entre homem e natureza.

Esta relação do homem com a natureza acontece de modo a proporcionar no homem uma superação das condições meramente naturais e existenciais imediatistas. Esta superação é a prática da consciência ${ }^{3}$, esta prática sendo o motor do humano, enquanto capacidade de produzir o mesmo de forma real e completa. De tal maneira que Feuerbach assim afirma:

Esta consciência é algo que se explica em Feuerbach, como sendo a condição humana do auto reconhecimento, e ainda como condição de auto identificação da essência. Esta consciência é a condição humana que torna possível justamente o entendimento de essência humana para o próprio homem, ou seja, aquilo que o homem necessita para seu auto entendimento. Porém, tal explicação sobre a consciência apresentar-se-á de forma mais completa na sequência deste texto.

\begin{tabular}{|c|c|c|c|c|}
\hline Rovita Dialectus & Ano 5 & n. 12 & Janeiro - Julho 2018 & p. $284-302$ \\
\hline
\end{tabular}


$\mathrm{Na}$ natureza, os graus de desenvolvimento não têm, por isso, um significado exclusivamente histórico; são sem dúvida momentos, mas momentos da totalidade simultânea da natureza, e não de uma totalidade particular, individual, que é por sua vez apenas um momento do universo, isto é, da totalidade da natureza (FEUERBACH, 2012, p. 25).

O que se demonstra na natureza não é um grau de desenvolvimento, onde o homem só tem sua participação garantida em uma fase deste processo. Os momentos históricos são construídos, porém esta construção acontece em concomitância com a totalidade do universo, que é esta produção da natureza em totalidade. Em outras palavras, a natureza se constrói e se fundamenta em sua totalidade material e não de maneira ideal. O que acaba por configurar uma posição imediatista da natureza, visto que a natureza em Feuerbach é parte integrante do humano e não apenas uma condição constituinte do humano, a natureza não é apenas um elo no processo de constituição do humano. Vale ressaltar que essa natureza enquanto constituinte do humano se configura desta forma na condição de relação do homem com seu produto essencial, e não a natureza como condição física material.

Todavia esta natureza possui em si a fonte da essência do homem, uma vez que é fonte da produção deste reconhecimento que o homem precisa fazer de si. A natureza é ponto principal nesta condição de reconexão, visto que é na natureza que se evidencia a condição material e real do homem e, é na natureza que aquilo que se entende por material está. Eduardo Chagas assim defende:

Um novo tempo deve, segundo ele, começar, quando o homem avaliar corretamente seu significado e reconhecer sua condição dada pela natureza, isto é, quando reconhecer sua finitude, transitoriedade e mortalidade de sua existência. Por conseguinte, o homem não deve mais procurar o fundamento para sua existência, post-mortem no além, como propõe a doutrina cristã da imortalidade, mas, pelo contrário, na própria natureza. Na análise de Feuerbach, quando o homem chega à consciência de sua finitude e mortalidade, alcança ele coragem e confiança para começar uma vida nova puramente terrena, ou seja, no interior dos limites da natureza (CHAGAS, 2009, p. 40).

Aqui, portanto, se configura e se efetiva a necessidade que nosso autor tem de explicar o homem a partir do concreto. Para Feuerbach, o homem completo é alcançado dentro de uma finitude real, ou seja, é preciso explicar-se e compreender-se dentro da finitude. A explicação da essência encontra-se na natureza, encontra-se no real e no reconhecimento deste real enquanto condição material de explicação. Aquilo que aqui é salientado, é a relevância de destacar os limites da natureza, enquanto natureza propriamente sensível, como fonte de explicação e como fonte ainda de conexão com a essência do homem que foi perdida ao longo da construção do mesmo homem.

\begin{tabular}{|l|l|l|l|l|}
\hline Q Povista Dialectus & Ano 5 & n. 12 & Janeiro - Julho 2018 & p. 284-302 \\
\hline
\end{tabular}


A ponte para se pensar a oposição entre Feuerbach e Hegel consiste em definir que, enquanto Hegel tem como fonte de reflexão o abstrato e o ideal, em Feuerbach, a fonte da reflexão sobre o homem sustenta-se no próprio homem determinado e real. Feuerbach não consegue compreender como a formulação idealista de Hegel sobre a formulação do "Espírito Absoluto", propõe o real. Eduardo Chagas, em um de seus textos, intitulado "Projeto de uma nova filosofia como afirmação do homem em Feuerbach”, assim defende:

[...] o que em Hegel ocupa centro da filosofia, o espírito absoluto, é considerado em Feuerbach como um produto do homem; o que em Hegel era meramente uma automediação do espírito, a natureza, ocupa, no entanto, em Feuerbach, o centro e se converte em fundamento do espírito; enquanto Hegel parte de um pensamento sem pressupostos, sem distinguí-lo de seu objeto, Feuerbach, ao contrário, parte imediatamente dos seres empíricos, reais; enquanto Hegel inicia sua reflexão a partir da categoria mais abstrata e mais indeterminada, o espírito, Feuerbach, ao invés, começa com o concreto, o finito; enfim, enquanto Hegel toma o ser em sentido abstrato, Feuerbach entende por ser determinado, real, efetivo (CHAGAS, 1992, p. 33-34).

Em oposição à filosofia de pensamento abstrato de Hegel, Feuerbach se dedica a pensar e esclarecer o homem a partir de um posicionamento que possibilite pensar o homem dentro de uma proposição do real. Aquilo a que nosso pensador se propõe, e em consequência, aquilo que o distancia de Hegel, é a condição de pensar o homem de forma material, oposto ao abstrato idealista de seu mestre.

O que Feuerbach discute ao longo de sua produção filosófica é o que se configura como essência humana, que é pensar o real de forma a desmistificar essa condição de inferiorização. A proposta versa sobre como esta essência deve orientar o reconhecimento do humano e, por fim, como a mesma necessita ser entendida por este enquanto sua essência e não algo cindido dele mesmo, ao passo que apenas com ela ou com seu despertar, ou mesmo ainda com o reconquistar desta essência. Essa é a superação da alienação causada pela externalização da mesma essência, sendo isto posto quando o homem promove a criação de um ser controlador e perfeito - a saber, Deus -. Feuerbach desenvolve tal discussão, visto a importância do homem em recuperar esta essência, uma vez que, como o pensador identifica a essência do homem está em sua crença no próprio humano, contanto que as capacidades humanas - a saber, vontade, amor e razão - que tornam possível a consciência, sejam reconhecidas por ela mesma de forma totalizante.

O resgate da essência humana consiste na capacidade do homem de reconhecer tal força como uma chama que possibilita a si um entendimento real e material do em gênero. Este resgate possibilita para o entendimento do significado de ser humano, talvez de forma até mesmo incompleta. Porém, é justamente este entendimento que o homem necessita recuperar,

\begin{tabular}{|l|l|l|l|l|}
\hline Qevista Dialectus & Ano 5 & n. 12 & Janeiro - Julho 2018 & p. 284-302 \\
\hline
\end{tabular}


pois só quando entende que a força positiva da religiã,o que é a força da crença, sendo esta crença no próprio homem, é possível estabelecer o contato real com sua essência, que é aquilo que orienta o humano em sua completude.

Feuerbach afirma que esta crença em si move a história e justifica a existência deste ser em gênero que é o homem. O processo de interpretar o homem parte do próprio, de maneira que possibilite a percepção dos atributos humanos enquanto atributos humanos e não enquanto atributos divinos e exteriores, como até então se apresentam na explicação da fonte da essência humana na filosofia especulativa, da qual o pensamento de Hegel é um dos principais exemplos.

Trata-se do fato de identificar esta essência enquanto consciência, sendo esta a consciência do gênero ou da humanidade, que se configura como entendimento do humano enquanto humano. Esta essência encontra-se no limiar do reconectar-se do homem com ele próprio que se caracteriza como o reconectar-se com a humanidade. De tal modo que, essa consciência é a capacidade de reconhecimento do homem enquanto homem para que se entenda a realidade a partir da realidade puramente humana e sensível.

A fonte da essência humana encontra-se dentro do homem em gênero, que é, 294 afirma Feuerbach, o objeto de si mesmo. Sendo que o homem se identifica dentro deste ciclo que se completa quando o humano entende que o ponto central da consciência é o humano que sente, o humano que ama e o humano que pensa, o que torna possível o despertar do entendimento adequado da essência humana.

A consciência do infinito é a auto conservação a auto realização, que acontece mediante o reconectar-se com a realidade humana, sendo esta realidade acessível ao homem, o qual supera a infantilidade e a inocência de se perceber como ser falho e sem atributos e, em contrapartida, religar-se com aqueles atributos externalizados e conferidos a um ser eterno e infinito - a saber, Deus - reconhecendo-os como atributos e qualidades estritamente humanas e reais. Assim, afirma Feuerbach:

\footnotetext{
Na relação com os objetos sensíveis é a consciência do objeto facilmente discernível da consciência de si mesmo, mas no objeto religioso a consciência coincide imediatamente com a consciência de si mesmo. O objeto sensorial está fora do homem, o religioso está nele, é mesmo íntimo. Por isso, a consciência que o homem tem de si mesmo (FEUERBACH, 2013, p.44).
}

Dessa forma, o objeto religioso, estando dentro do homem, é aquilo que se configura como a essência que se encontra em si e no reconhecer-se enquanto recobrar da consciência, que é algo que se evidencia na discussão entre homem e ser genérico, sendo esta

\begin{tabular}{|c|c|c|c|c|}
\hline Q Rovista Dialectus & Ano 5 & n. 12 & Janeiro - Julho 2018 & p. $284-302$ \\
\hline
\end{tabular}


discussão uma ação que parte do próprio homem, que é este ser munido de sua tríade amor, razão e vontade. E, desta maneira, entendendo-se como este ser real que encontra o entendimento de si dentro de si, dentro do outro e dentro da realidade sensível e de maneira alguma em uma realidade suprassensível e metafísica composta de seres metafísicos.

Isto apresentado, a primeira preocupação que se tem é identificar o que é esta consciência que torna possível o resgate desta essência humana, o que é este homem em gênero, o que faz deste um ser completo e ainda, preocupa-se neste momento em esclarecer a necessidade de se pensar este homem dentro da dualidade eu e tu, que se configura como dualidade do eu com o outro eu, do eu com o outro e do eu com a realidade. A afirmação do homem em gênero vai acontecer frente a este debate estabelecido entre homem real que se percebe em uma realidade completamente desdivinizada, completamente material que é consequentemente finita e, homem ideal que se percebe a partir de uma condição abstrata, formulando uma dependência para com esta condição abstrata e, não para a realidade humana finita. Tanto que o nosso pensador assim se posiciona em seu texto Pensamentos sobre morte e imortalidade:

[...] a vida "não pode ser dada, nem presenteada [...], pois somente vive aquilo cujo ser e essência é sua vida mesma"; "vida é unidade de essência e ser, vida só há ali, onde se dá uma absoluta identidade consigo mesma”. Portanto, o que vive, tem o fundamento e o princípio de seu ser em si mesmo; só aquilo, que é em si mesmo e de si mesmo, tem vida. Vida não quer dizer nada mais do que ser o fundamento de si mesmo (FEUERBACH apud CHAGAS, p. 48, 2009).

"Só aquilo que é em si mesmo e de si mesmo, tem vida". Neste sentido só um ser real é capaz de se perceber enquanto ser vivente, em outras palavras, só um ser finito e consciente desta finitude que o compõe é capaz de se possuir, ou seja, de possuir a sua essência. Isto posto, tal possibilidade só é capaz de acontecer, quando o homem se percebe enquanto ser consciente e possuidor desta consciência, o que se apresenta como preocupação neste momento explicar a consciência.

\subsection{O QUE É A CONSCIÊNCIA?}

O motivo de tal questionamento é a necessidade de explicar em que consiste a consciência. O homem é o único ser dotado de consciência, ou seja, o único dotado da percepção dele mesmo, e sendo assim o único capaz de produzir relação dele com o outro na forma dialética eu e tu. Mas o que de fato é esta consciência e como ela acontece no homem? Feuerbach vai afirmar que a consciência é a religião, ou seja, a crença do homem real que se

\begin{tabular}{|c|c|c|c|c|}
\hline Rovita Dialectus & Ano 5 & n. 12 & Janeiro - Julho 2018 & p. $284-302$ \\
\hline
\end{tabular}


vê no mundo e que produz sua existência e domina sua essência a partir da dominação ou do apoderamento desta consciência.

Feuerbach ainda destaca em um de seus textos - a saber, Necessidade de uma Reforma da Filosofia - a seguinte afirmação: "Na origem, a religião é fogo, energia, verdade; toda religião começa por ser estrita e incondicionalmente religiosa, mas, com o tempo, esgotase, torna-se infiel a si mesma, indiferente, submete-se à lei do acto" (FEUERBACH, 2002, p.15), justamente para destacar que este caráter de fogo que queima, queima como fonte de combustão que orienta o homem em sua trajetória rumo à essência, tal fogo deve ser levado em consideração, uma vez que o mesmo pode ser entendido como fonte da consciência, ou propriamente da consciência em si.

O problema consiste em entender esta religião apenas como esta energia, sendo que a condição e a percepção da consciência estão ligadas diretamente a percepção do homem enquanto ser finito e, de maneira alguma, ligada a percepção de um ser infinito que nos concede tal consciência. O próprio Feuerbach afirma: "Um ser realmente finito não possui a mínima ideia, e muito menos ciência, de que seja um ser infinito, porque a limitação do ser é também a limitação da consciência" (FEUERBACH, 2013, p. 36), salientando que a capacidade de reconhecimento é uma qualidade especificamente humana, e que deve ser feito por parte da consciência.

A consciência deve ser aquilo capaz de fazer com que o homem se perceba no mundo como um ser em gênero, como um ser integral e sagrado ${ }^{4}$. Este ser em gênero, deve ser um ser que percebe a tríade humana - a saber, amor, razão e vontade - uma vez que o homem é um ser que sente, que pensa e que quer. A consciência ou percepção de si deve ser estruturada neste ser completo e não em um ser exteriorizado que não entende as qualidades humanas como sendo humanas. Mas sim qualidades advindas de fora. $\mathrm{O}$ ser consciente deve ser aquele capaz de perceber a infinitude dentro de si. Esta infinitude entendida como essência humana ou homem completo - entendido como homem em gênero -, de tal maneira que se apresenta esta necessidade de reconhecimento da essência em Feuerbach, que os comentadores Benedicto Arthur Sampaio e Celso Frederico, assim afirmam:

4 A ideia de sagrado, embora não seja tratada propriamente por Feuerbach, fundamenta-se aqui na condição naturalista que defende a posição de que o homem possui uma santidade em si, é aquela qualidade única do homem. Aqui sendo aquilo que tratamos por essência humana - algo que é tratado e explanado na obra $A$ Essência do Cristianismo - que, por conseguinte é o reconhecimento do ser em gênero, que é justamente este ser munido dos atributos humanos, os quais despertam a consciência e possibilitam o reconectar com a essência.

\begin{tabular}{|c|c|c|c|c|}
\hline Rovita Dialectus & Ano 5 & n. 12 & Janeiro - Julho 2018 & p. $284-302$ \\
\hline
\end{tabular}


Em suma, segundo Feuerbach, a vida subjetiva do homem pode ser entendida como a presença do objeto universal natural específico no interior do indivíduo, visto que a consciência, para ele é essencialmente universal e infinita (SAMPAIO, FREDERICO, 2009, p. 65).

A consciência é, em Feuerbach, o significado do homem, pois é aquilo que explica homem, visto que o homem não é um ser cindido. O objeto da consciência do homem que deve ser o predicado ou objeto dele próprio deve estar fundado em si mesmo, uma vez que Feuerbach identifica que o reconhecimento do humano está no próprio humano - no ser em gênero. Assim afirma Alice Aleixo:

A especificidade humana reside na capacidade que o homem tem de ser consciente
de si, ou seja, de ter como objecto o seu próprio género. O homem é um eu e um tu e
é na consciencialização da intersubjectividade que o homem se apreende como
membro da espécie. Enquanto no animal a vida interior coincide com a vida
exterior, no homem elas são distintas. A vida interior é a relação que o homem
estabelece com a sua essência universal (ALEIXO, 2009, p.9).

A consciência é a capacidade de introspecção para alma humana que se define como alma que pensa, que sente e que ama, a partir de sua própria realidade e sua relação do eu e o tu, que se fundamenta nesta sua realidade, sendo esta alma entendida como a essência humana. Esta consciência se justifica enquanto capacidade de interiorização do homem. Esta capacidade de se internalizar possibilita ao homem a condição de reconhecimento, possibilita a contingência de produzir-se enquanto humano. A consciência é aquilo que se chamou a pouco de capacidade de introspecção, qualidade que só é possível ao homem que possui essa faculdade do dialogar consigo, faculdade essa que é fonte de identidade para o homem. Tal afirmação é evidenciada nos respectivos comentadores: "É o homem, enquanto alma humana, não só o único critério, mas também a única identidade, a única mediação da realidade, a sede onde se situa a infinitude dos seres finitos e reais" (SAMPAIO, FREDERICO, 2009, p.64). Esta realidade deve ser entendida como uma consciência que se define especificamente por ser universal, isto significando que não existe uma negação da consciência e, por conseguinte, um vir-a-ser, mas sim um reconhecimento real e constante do humano a partir do humano.

Esta consciência é tanto exterior, quanto interior, que se produz a partir do reconhecimento do humano com ele mesmo e alicerçado nesta relação com a carne, por isso não há uma negação, porque depende em certa medida do entendimento de ser enquanto ser material e enquanto ser espírito. Afirmam Benedicto Arthur Sampaio e Celso Frederico:

[...] a espécie humana, o gênero natural do homem, é o horizonte de onde a ciência e a verdade; que fica implicitamente proposta uma gnosiologia fundada na ordem natural do ser humano e, por isso, muito a gosto de um certo naturalismo

\begin{tabular}{|c|c|c|c|c|}
\hline Q Rovista Dialectus & Ano 5 & n. 12 & Janeiro - Julho 2018 & p. $284-302$ \\
\hline
\end{tabular}


classificatório em Feuerbach, mas já naquela época ultrapassado por outro mais dinâmico (basta lembrar Goethe, Lamarck etc.); que a vida subjetiva, genérica, é somente humana, pois só o homem é capaz de se relacionar com sua espécie sem a presença exterior de outro espécime; que o homem nunca está sozinho porque é ao mesmo tempo um e outro enquanto tem o geral no interior de si mesmo (SAMPAIO et. al., 2009, p. 65).

Este reconhecimento do homem enquanto humano parte inclusive desta relação com o tu, mas este tu é um tu inclusive interior, este tu é a capacidade humana de conversar consigo mesmo, exteriorizando-se ou não. Pois o homem é este ser capaz de se perceber na sua singularidade, e ainda capaz de se perceber como outro como um ser que se objetiva que se lança na realidade e que ainda se percebe através desta sua presença na mesma realidade. Feuerbach acaba por salientar o que é a fonte da consciência, a forma como ela trabalha e funciona e, como ela está fundamentada na condição do real e material. Para Feuerbach entender a consciência passa pelo crivo de entendimento do homem para com o homem, como sendo um ser real e material, que se explica a partir desta condição, que possibilita ao mesmo o contanto com esta consciência. Evidenciando que a abstração proposta pelo idealismo não existe, uma vez que a proposta idealista de conexão com a essência humana está fundamentada na condição ideal e não concreta.

O que se apresenta na posição de Feuerbach acerca daquilo que pode ser entendido enquanto realização da consciência e, enquanto entendimento de essência, é, portanto, que tal acontecimento acontece e se fundamenta na condição e na estrutura do real. Manifesta-se também que aquela dialética proposta pelo idealismo como forma de reconhecimento desta essência não acontece em uma realidade ideal, que tem por fonte a ideia, mas sim que acontece em uma realidade real que tem por fonte o material - a saber, este material é a própria realidade humana.

Esta percepção de si parte em certa medida inclusive da relação com o outro homem. Dessa forma, essa relação com o outro se toma elo importante para a produção da consciência e ainda o reconhecimento da essência dentro da realidade real material e, de maneira alguma, a produção desta essência ou, mesmo que seja a percepção desta essência, deve acontecer de maneira reflexiva, que acaba por anular o dado aparente, ficando apenas com a relação Idealista. Esta abstração questionada e superada por Feuerbach acontece uma vez que o homem não percebe no ato reflexivo apenas a possibilidade de produção ou mesmo de identificação da consciência do próprio humano.

Esta abstração que corresponde a uma ação efetivamente psicológica, não brota da ação filosófica e, não funciona partindo da mesma abstração como ponto de referência ou

\begin{tabular}{|l|l|l|l|l|}
\hline Q Povista Dialectus & Ano 5 & n. 12 & Janeiro - Julho 2018 & p. 284-302 \\
\hline
\end{tabular}


ainda como ponto de partida. Para a produção da consciência ou percepção do homem em gênero que corresponde respectivamente ao humano real dotado de sua essência completa, faz-se necessário que o homem esteja munido em sua totalidade de uma razão, uma vontade e um sentir que fazem do homem este ser consciente de si no sentido de possuir uma identidade.

A função da Filosofia em Feuerbach é justamente a de proporcionar este despertar da consciência que só pode acontecer em contato com a realidade. De tal forma que o papel da Filosofia deve ser o de assumir a consciência do ser em gênero, tomando como papel este articular do humano com o "eu e o tu" (o outro eu), com o "eu e a realidade", com o "eu e o outro", de forma a apresentar a consolidação do exercício consciente do homem em gênero. Utilizando-se de uma relação total com o empírico, sendo este empírico usado como fonte da correlação existente entre esta esfera do ser humano em gênero com a sua realidade exterior e interior.

Assim sendo afirmam Benedicto Arthur Sampaio e Celso Frederico: "A essência do cristianismo, o enigma revelado de Cristo é o homem, não é Deus" (SAMPAIO, FREDERICO, 2009, p. 65). A essência e explicação sobre o próprio homem estão nele próprio e não em algo exteriorizado a ele - a saber, Deus - sendo assim, a produção da consciência parte do humano real e constante e de maneira alguma pode partir de uma realidade superior que é irreconhecível pelo humano e ainda incabível de reconhecimento visto que este não entende tal realidade. Esta essência está presente no homem concreto dentro desta universalidade com o interior de si, ou seja, o entendimento e reconhecimento do humano parte da universalidade e da totalidade de tomar ciência de seus atributos que o constituem como um homem em gênero.

Neste sentido, esta abstração que propõe o idealismo, ou ainda, esta dualidade do homem como exterioridade de si ou como essência cindida, promove a perda ou até mesmo a não percepção de sua consciência. Uma vez que, essa dependência proposta pelo idealismo de um ser absoluto, não promove no humano a capacidade de conhecer ou ainda de identificar esta consciência a partir de si e de uma realidade que parte do humano. À medida que a consciência se produz e se torna identificável como resultante da relação sujeito-objeto, visto que este objeto é a primeira instância, o próprio sujeito que se identifica em sua totalidade justamente por existir nesta relação de eu e o eu, do eu e o tu - esse tu entendido como o outro eu -, do eu com o tu e do eu com a realidade.

O homem é a manifestação da consciência enquanto predicado do próprio humano, o humano é, portanto, a essência manifesta desta consciência. Esta consciência parte do evidenciar deste predicado deste ser real e material que revela e toma conhecimento de si

\begin{tabular}{|c|c|c|c|c|}
\hline Q Rovista Qialectus & Ano 5 & n. 12 & Janeiro - Julho 2018 & p. $284-302$ \\
\hline
\end{tabular}


enquanto ser completo partindo de si, do outro e da realidade como um todo e nada exteriorizado, o genérico, ou homem em gênero, é este ser completo que se realiza e se afirma a partir desta própria consciência de si que se produz com base neste relacionar-se consigo e deste relacionar-se com o real.

Esta compreensão do gênero, para Feuerbach, não está nesta abstração que parte, segundo o idealismo, da proposta onde essa consciência ou mesmo autoconsciência, como intitula Hegel, está exteriorizada, sendo necessário o relacionar com o objeto para alcançar tal autoconsciência, a qual lhe concerne à realização suprema do idealismo abstrato. Tornandose, assim, possível o alcance desta autoconsciência apenas de forma exterior, para a qual o humano não poderá se reconhecer. Este homem em gênero se satisfaz e se realiza partindo da pura percepção deste humano, isso se caracteriza, portanto, como o "absoluto" em Feuerbach, visto que se configura como o alcance da universalidade do homem como ser genérico, que é a instância consciente e o auto esclarecimento, que parte deste ser real que é o humano e não de um ser abstrato.

Neste sentido, toda modificação - sendo ela de qualquer princípio -, só pode ocorrer na atividade exclusiva da consciência humana. Só se torna possível qualquer ação partindo do entendimento dos atributos humanos que são acessíveis por meio da consciência, algo que só é possível partindo das virtudes humanas da razão, do amor e da vontade. O homem só pode ter acesso a esta consciência, se a mesma for entendida enquanto qualidade sensível do homem. Para Feuerbach apenas um ser real e sensível, colocado e entendido dentro de sua realidade sensível, é capaz de despertar essa consciência, e por sua vez reconectar-se com sua essência. Eduardo Chagas assim afirma sobre o entendimento de ser sensível por parte de Feuerbach:

\footnotetext{
Em contraste, pois, com a filosofia hegeliana, que crê poder apreender o objeto por via puramente abstrata, Feuerbach evidencia que o objeto é dado somente pelos sentidos, não pelo pensamento. Só um ser sensível é um ser verdadeiro, real e só mediante os sentidos se revela o segredo do ser. Esta intuição sensível princípio de determinação dos objetos, está na reverberação feuerbachiana, estritamente ligada às paixões, que são o sinal revelador de existência, pois só é o que é objeto de sensação. Neste sentido, o pensamento sem sensação e sem paixão abole a diferença entre ser e não-ser (CHAGAS, 1992, p. 35-36).
}

Os sentidos explicam o real, que explica a consciência, que é aquilo que explica o homem. Em outras palavras, a consciência se explica pelo real e sensível, que consiste no entendimento do próprio homem que se efetiva como esta consciência. $\mathrm{O}$ entendimento nesse sentido se configura a partir do próprio sujeito em relação consigo e com o outro, ou seja, o entendimento desta produção humana enquanto capacidade estritamente

\begin{tabular}{|l|l|l|l|l|}
\hline Q Povista Dialectus & Ano 5 & n. 12 & Janeiro - Julho 2018 & p. 284-302 \\
\hline
\end{tabular}


humana que se identifica enquanto consciência. Isto se configura enquanto homem em gênero, que é este ser completo ou que alcança completude por meio do recuperar a essência.

\section{REFERÊNCIAS}

\section{OBRAS DE FEUERBACH}

FEUERBACH, L. A Essência do Cristianismo. 4 ed. Trad. José da Silva Brandão. Petrópolis, RJ: Vozes, 2013.

FEUERBACH, L. Essência de La Religion. Trad. Tomás Cuadrado. Madrid, Espanha: Rosário, 2005.

FEUERBACH, L. Pensamientos sobre muerte e inmortalitad. Trad. José Luis García Rúa. Madrid, Espanha: Alianza Editorial, 1993.

FEUERBACH, L. Para a Crítica da Filosofia de Hegel. Trad. Adriana Veríssimo Serrão.

São Paulo, SP: LiberArs, 2012.

FEUERBACH, L. Preleções Sobre a Essência da Religião. Trad. José da Silva Brandão Petrópolis, RJ: Vozes, 2009.

FEUERBACH, L. Princípios da Filosofia do Futuro. Trad. Arthur Morão. Lisboa, Portugal: Edições 70, 2002.

\section{TEXTOS E COMENTÁRIOS}

CHAGAS, E. F. Homem e natureza em Ludwig Feuerbach. Fortaleza, CE: Edições UFC, 2009.

CHAGAS, E. F. Natureza e liberdade em Feuerbach e Marx. Campinas, SP: Editora Phi, 2016.

SAMPAIO, B. A.; FREDERICO, C. Dialética e materialismo: Marx entre Hegel e Feuerbach. Rio de Janeiro: UFRJ, 2006.

TOMASONI, F. Luwig Feuerbach e a fratura no pensamento contemporâneo. São Paulo: Edições Loyola, 2015.

ZILLES, U. Filosofia da Religião. 6ª ed., São Paulo: Paulus, 2015.

\section{ARTIGOS EM PERIÓDICOS}

ALBINATI, A. S. Feuerbach: Fundamentos para uma Ética da Sensibilidade. Revista Dialectus. Ano 2, n. 6, jan. - ago. 2015, p. 75-84.

\begin{tabular}{|l|l|l|l|l|}
\hline Q Povista Dialectus & Ano 5 & n. 12 & Janeiro - Julho 2018 & p. 284-302 \\
\hline
\end{tabular}


ALEIXO, A. Ludwig Feuerbach. Um Manifesto Antropológico. Artigos LUSOSOFIA. Disponível em: http://www.lusosofia.net/textos/aleixo_alice_feuerbach.pdf. Acesso em $01 \mathrm{de}$ junho de 2016.

CHAGAS, E. F. A natureza como negação da imortalidade da alma no jovem Feuerbach. Revista Princípios Natal. v.16, n. 26, jul./dez. 2009, p. 35-51.

CHAGAS, E. F. A vontade é Livre? Natureza e Ética em Ludwig Feuerbach. Revista Dialectus. Ano 2, n. 6, jan. - ago. 2015, p. 1-34 .

CHAGAS, E. F. A Religião em Feuerbach: Deus não é Deus, mas o Homem e ou Natureza Divinizados. Revista Dialectus. Ano 2, n. 4, jan. - jun. 2015, p. 78 - 91.

CHAGAS, Eduardo F. Projeto de uma nova filosofia como afirmação do homem em Ludwig Feuerbach. Teoria \& Praxis. Revista de Ciências Humanas e Política, nº 4, Goiânia (GO), p. 31-6, 1992.

CANDIOTI, M. El carácter enigmático de las Tesis sobre Feuerbach y su secreto The Enigma of the Theses on Feuerbach and the Secret thereof. ISEGORÍA. Revista de Filosofía Moral y Política, n. 50, p. 45-70, enero-junio, 2014.

GOOCH, Todd. "Ludwig Andreas Feuerbach". The Stanford Encyclopedia of Philosophy (Winter 2016 Edition). Edward N. Zalta (ed.). Disponível em : http://plato.stanford.edu/archives/win2016/entries/ludwig-feuerbach/. Acesso em 23 de novembro de 2016.

LIMA, F. J.G. Feuerbach e o Processo de Secularização Ocidental. Outramargem: revista de filosofia, Belo Horizonte, n. 2, $1^{\circ}$ semestre de 2015.

MARTÍNEZ, J. G. Eudemonismo y Libertad en la Filosofía Moral de Ludwig Feuerbach.

Revista Dialectus. Ano 2, n. 6, jan. - ago. 2015, p. 60-74.

MELO, R. G. Crítica de Feuerbach às religiões em defesa do homem integral e da natureza não-instrumentalizada. Revista Intuitio. Porto Alegre, v. 4, n. 2, Nov. 2011, p. 224-236.

MONTEIRO, F. P. O Materialismo no Debate Feuerbach, Stirner e Marx: Relevâncias para a História Social Contemporânea. Revista de Teoria da História. Ano 2, n. 5, jun. 2011.

\begin{tabular}{|l|l|l|l|l|}
\hline Q Povista Dialectus & Ano 5 & n. 12 & Janeiro - Julho 2018 & p. 284-302 \\
\hline
\end{tabular}

